\title{
The Time Factor and Compact Course Development
}

H.H. Stern

Editor's Note: This previously unpublished paper was prepared by Dr. Stern for the Marburg Symposium on Compact Courses organized by the Fédération internationale des professeurs de langues vivantes (FIPLV) in 1981. At first glance, it may appear to deal with foreign language teaching rather than ESL. How- ever, a second look will show its relevance to the teaching of English as a second language to Canada's native people, to francophones in Quebec, New Brunswick and other areas with French school systems, in certain multicultural settings, and in other countries. PML

The idea of the compact course, which was the topic of an international symposium held in Marburg, West Germany in September 1981, was largely prompted by criticism of the typical traditional language course in European secondary school systems. As the Marburg symposium expressed it:

In many national education systems at the present time, one foreign language is studied for a limited number of hours each week throughout the period of compulsory secondary education. It is widely considered that the spreading of the limited curriculum time available for the study of language over such an extended period weakens the motivation of pupils and teachers. This leads to boredom, underachievement and the premature abandonment of language study by many pupils, who may finish up with no more than a fragmentary knowledge of a single foreign language, which they cannot, and no longer wish to use for effective communication.

Compact courses suggested as a remedy for these weaknesses of the traditional language course were characterized at the symposium by three features: 1) specified short-term objectives, 2) a clearly defined timespan, and 3 ) the self-contained nature of each compact course within a broader system of language education. In such a system, it was argued, "pupils would pursue, in a more concentrated way, a series of clear and useful objectives." This, it was claimed, would lead to improved motivation and greater concentration of effort. It would also be a more flexible system "which would permit and encourage the achievement and recognition of 
useful levels of proficiency in a number of languages" with obvious advantages for a multilingual and international education. ${ }^{1}$

Whether or not we regard the criticisms of the conventional language courses as justified and whether or not the expectations of the compact course system are reasonable, one thing is certain: in a compact course the time available for the language course is modified, either reduced or differently distributed by comparison with conventional language programs, and the courses envisaged are offered in a more concentrated form within a shorter than "normal" or "traditional" time span. It is because of this emphasis on reduction and concentration of time (from which flow a number of consequences for course design, teaching method, and materials) that it is important to look more closely at the time aspect which plays such an important role in this innovation.

In advocating compact courses we deliberately manipulate the time element. A great deal of experience has already been gathered on the time factor in language teaching. On the whole, research suggests that increases in time lead to higher proficiency. Insufficient time allowance has been considered as one of the most important causes of inadequate language learning. Consequently, the compact course, by reducing the demand for time seems to run counter to this general research finding. How are we to interpret this anomaly? Is reduction in time compensated for by greater concentration? In order to find an answer to these questions let us briefly review experience and research on the time factor in language pedagogy.

\section{EXPERIENCE ON THE TIME FACTOR}

Until World War II, when languages were thought of mainly as secondary school subjects, the accepted time allowance was the daily or nearly daily 40-, 45- or 50-minute lesson over a period of two, three, or more years, and, as we have already noted, this is still very much the accepted pattern in European and Canadian school systems today. In universities, too, time slots set aside for language learning have been determined mainly by tradition and curriculum priorities, and not for any specific pedagogical reason. On the whole, time allowances were in the past-and they often still are today - treated as a given to which language teaching has to adjust itself, rather than as a factor to be manipulated to make language learning more effective.

During World War II, in military and diplomatic language training, various time allocations were tried, and among them a concentrated, intensive, or immersion approach of four to six or more hours per day became popular. On the basis of these experiences, intensive language learning, particularly for adults, became a recognized pattern of language 
instruction after World War II. For example, language training for business, government, and sometimes in universities, adopted a full-time, intensive language program. ${ }^{2}$ The present-day interest in compact courses at the school level largely results from this more flexible approach to timing outside regular school settings.

A consequence of this varied organization of such intensive programs was the attempt to predict more accurately the time allowances to be made to learn a language to given levels of proficiency. One such estimate of the time requirements for learning a language is shown in Table 1 (taken from Cleveland, Mangone, and Adams 1960). This table is interesting in many respects. It shows that by 1960 , on the basis of practical experience, a good deal of sophistication of knowledge on the time factor had been attained. First of all, the table takes into account the necessity to relate time estimates to the levels of proficiency to be reached. It is not possible to give a satisfactory answer to the question: "How long does it take to learn French?" But if we previously define the level of proficiency, an estimate is possible. Thus, the table shows three levels: Level $I$ is a minimum speaking proficiency to satisfy routine travel requirements. Level II is "Basic familiarity with proficiency to conduct routine business within a particular field. Sufficient familiarity with the writing system, to read simple material with the aid of a dictionary." Level III represents a more advanced knowledge of the language; it implies fluency and accuracy in ordinary, everyday conversation and the capacity to talk about one's speciality, and the ability to read newspapers and documents with limited reference to a dictionary. The table shows that for the highest proficiency level, three to six times as much time allowance must be made than to reach Level I. The table further indicates differences in daily time allowance according to the intensity of course work. It distinguishes between one daily class hour plus two hours of study and practice for each class hour, i.e., three daily contact hours; two daily class hours plus four to six hours of study; three class hours plus four to six hours of study. Thirdly, it allows for time differences according to the foreign language aptitude of the learner, that is, it recognizes that an able learner needs less time than a slow learner. Finally, it is suggested that different languages require different time allowances. Thus, this table ingeniously summarizes the interaction between estimates of time needed and expected levels of proficiency, class time and contact hours, learner aptitude, and the difficulty of a language. It is exactly this kind of knowledge that research in subsequent years has further confirmed, and there is no doubt that in the organization of compact courses these factors will also have to be taken into account.

One should perhaps note at this point that in the United States much shorter sequences than in Europe are customary in foreign language 


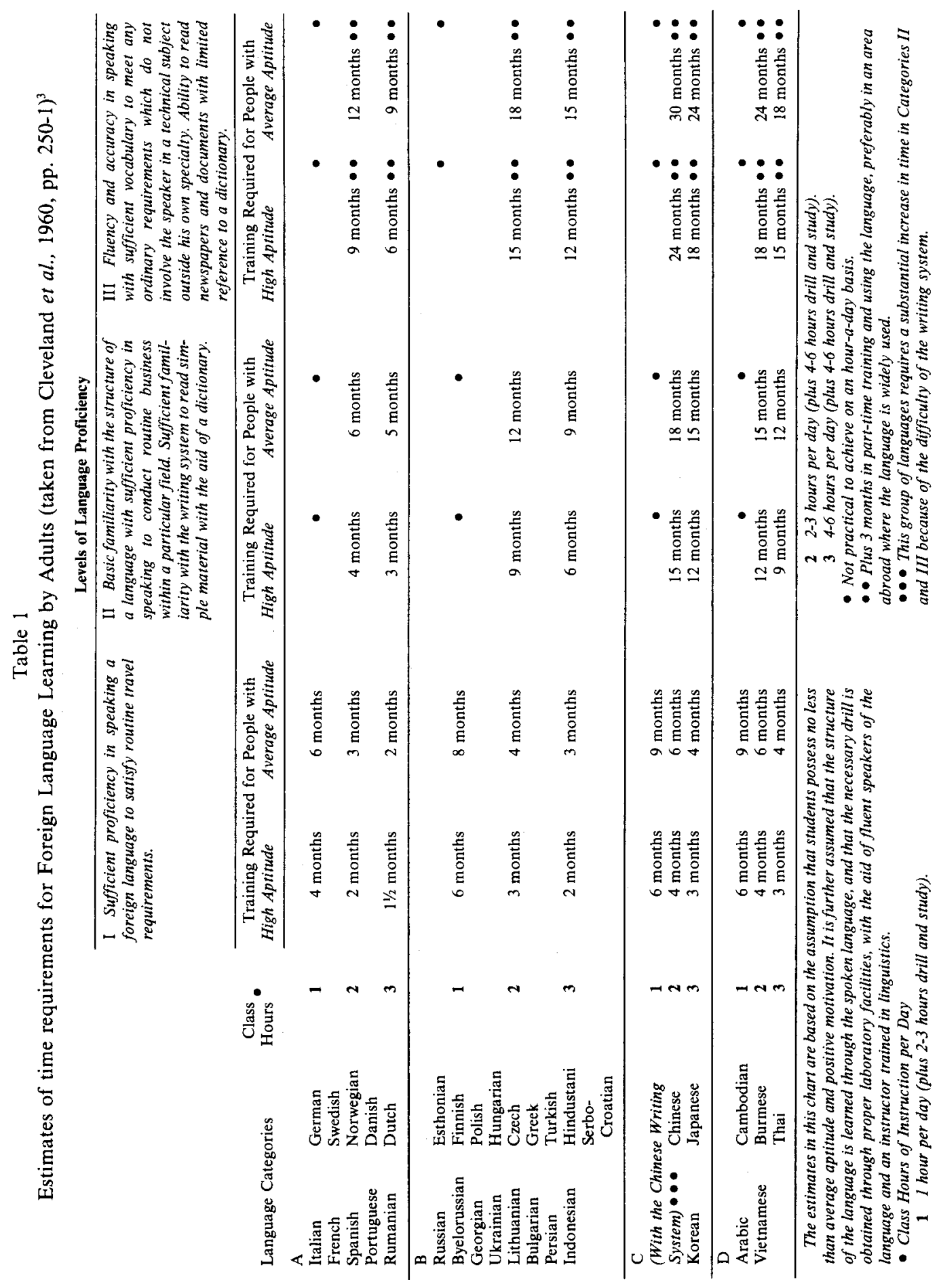


teaching at the school level: not the four, five, or more years of European school systems. Language courses in the U.S. are commonly two-year sequences. Therefore, by European standards they are already "reduced in teaching and learning time," and U.S. language educators have since the 1950s attempted to introduce longer rather than shorter courses. This was originally the rationale of foreign languages in the elementary school, the so-called FLES movement.

It is interesting to observe that the 1979 report of the U.S. President's Commission which was highly critical of foreign language achievement in that country urged "that language study begin in the early grades" (p. 29) but it specifically noted that the effectiveness of language study also "depends upon the time devoted to it," in addition to a number of other factors of which the report lists class size, a supportive atmosphere, well-trained teachers, and integration of early language instruction with higher levels of study (U.S.A., 1979). In other words, the U.S. report saw as a remedy for weakness in language proficiency, longer study, more time, and an earlier start, rather than in a more concentrated approach of the kind suggested by the concept of the compact course.

Another fact to bear in mind is that the spread of languages to the primary school in the 1950 s and 1960 s led to a trend in the opposite direction from that suggested by compact course development: the recommendation of very brief daily exposure to the language for, say, 15 or 20 minutes per day over a number of years in the primary school. This minimal approach to language learning stretched over several years has proved not to be nearly as effective as it had been hoped. ${ }^{4}$

Two monographs, one published in London (Hawkins and Perren, 1978) and the other in Washington (Benseler and Schulz, 1979), deal in detail with intensive courses, the London one with British experience mainly at the school level and the Washington one with U.S. experience mainly at the university level. Neither mentions compact courses. Hawkins and Perren (1978) include immersion courses and descriptions of sections bilingues. They also mention "crash courses." In a recent book which incorporates some of these experiences, Hawkins (1981), again without specifically referring to the compact course concept, outlines a scheme of stages of a language curriculum which, among other interesting features, includes intensive immersion-type advanced courses. This language curriculum has much in common with the ideas underlying the compact course principle. Benseler and Schulz (1979) confine themselves in their study to "those intensive courses and programs aimed at developing general language proficiency of students in traditional academic settings" (p. 8). They use as a defining characteristic for intensive courses that "they provide extended daily exposure to the language, ranging from two to eight hours per day, within a relatively short span of time" (p. 9). 
Similar criteria no doubt also apply to compact courses.

Language teaching, over a period of 40 years or so, has thus tried almost anything between the extremes of what in Britain is known as "dripfeed" and "full flow" without ever settling the time issue in a completely satisfactory way. This is no doubt due to the fact that a number of different considerations have entered into decisions on the time for language learning; very often costs, the urgency to achieve proficiency quickly, and time-table convenience or limitations have played as much a part in these decisions as have psychological or pedagogical considerations.

For example, U.S. wartime language courses were concentrated and intensive not so much because of a belief in the psychological advantages of massed over distributed learning, but because of the need to produce relatively high levels of proficiency rapidly and because, under conditions of military service, it was easier to arrange such programs on a full-time basis for a limited period than to spread them in small doses over a long time. That such an arrangement could also have pedagogic advantages was more a byproduct of these practical necessities. However, these advantages were rightly seized upon in the language pedagogy of the post-war years.

Whether time allocations were lengthened, reduced, or left as they were between the extremes, very little was done to verify whether the time allocations were appropriate for a given level of proficiency. Time allocations have been, and frequently still are today, a matter of tradition and guesswork. Sometimes claims are made for the value of certain time allocations for which there is little or no evidence.

In sum, it can be said that time allocations for language learning range from small amounts spread over a long period to large amounts concentrated in a limited period; these variations have been brought about by differences in teaching traditions, practical considerations of cost and convenience, as well as by psychological and educational arguments. With a few exceptions, very little was done until recently to obtain well founded information on the effectiveness of different time allowances and to study the particular problems that different time allocations entail.

This background of experience suggests a number of important consequences for the curriculum of compact courses to which we will draw attention later. The idea of the compact course is prima facie attractive because it liberates the time-table, the teacher and the student from the relentlessness and inflexibility of the monotonous long-term language course. It seems to by-pass an inherent problem of long courses: the difficulty of articulation and sequencing from grade to grade or level to level. It enables the curriculum planner to accommodate more than one language, and it should also be popular with teachers of other subjects 
who have always felt that language instruction demands too big a portion of the curriculum cake. But in advocating compact courses we should be cautious and not jump to conclusions about its advantages without having thoroughly investigated first what is feasible in the compact format, and how it works out in actual practice.

\section{RESEARCH ON THE TIME FACTOR AND SOME APPLICATIONS}

The American psychologist J.B. Carroll has been foremost in drawing attention repeatedly to the importance of the time factor in language learning and in advocating research on it. His model of school learning, which comprises but is not limited to language learning, included time for learning as one of the major components to take into account (Carroll, 1963). Time for learning provides the opportunity to learn. If this model is applied to language teaching, it leads to the hypothesis that, if all else is equal, the more total time is made available the higher the level that can be reached in a second language. Carroll (1967) found confirmation for this hypothesis, first, in a study of college students in which he related achievement in a second language to the length of time the second language had been studied. He found that those who had studied the language longest had reached the highest levels of proficiency. In the eight-country study undertaken by the International Association for the Evaluation of Educational Achievement (IEA), Carroll found again confirmation that the amount of French instruction to which the student is exposed is an important variable in accounting for the proficiency levels attained. He found very high correlations, 0.86 and 0.98 , between time and proficiency in French (Carroll, 1975: 180-185).

A similar conclusion was reached in the Canadian Ottawa French Project. This study was one of the most thorough investigations involving the time issue. ${ }^{5}$ The time variations studied ranged from 20 minutes a day to a full school-day of up to 300 minutes a day of immersion. One of the principal distinctions between the program choices, "core," "extended," and "immersion," in this large-scale experiment was the time allowed for French as a second language. The study showed very clearly that any increase in daily time leads to an increase in measured amount of language learning on objective foreign language tests.

The importance of time for language study, demonstrated by this kind of research, is reflected in practical measures taken by some educational systems. Here again Canadian experience is instructive. For example, the Ontario educational system has built its language teaching policy on the research findings on the time aspect. It has been calculated by Ontario administrators that a 20-minute daily lesson amounts to no more than 60 
hours instruction time in a school year. Accordingly, a conventional 40-minute daily lesson only constitutes 120 hours per year. On the other hand, to reach a modest basic knowledge of French it has been estimated by these educators in Ontario (Canada) that pupils must be exposed to approximately 1200 hours over their total school career. Thus to reach that time allocation with the conventional 40 -minute daily lesson 10 years of French as a second language would be required. A further estimate is that a useful working knowledge requires more generous time allowances i.e., 2100 hours. If a truly effective bilingualism is to be guaranteed the estimate jumps to over $\mathbf{5 0 0 0}$ hours as the total exposure over a pupil's school career which can only be reached by teaching other subjects in the second language in an "immersion" program. ${ }^{6}$

The recent work on time of language learning is relevant to compact courses in that it has introduced two important distinctions: total accumulated time and the question of distribution of time. Thus in a compact course a total of 60 hours can be reached by teaching 2 hours every day five days a week for six weeks. The kind of questions that research will have to come to grips with is how to decide on estimates of the total time needed and, given the normal constraints of time-tabling, the best distribution of time for reaching certain levels in a second language. Experience in intensive courses reported by Benseler and Schulz (1979) as well as research that I have been associated with (e.g., Stern, et al., 1976) suggests that larger daily amounts of teaching time over shorter periods are more effective than very small amounts, e.g., 20 minutes a day, over a much longer period. In principle, this finding supports the concept of compact courses, but it can only serve as a rough guide. It must also be remembered that the principle of increased time concentration does not apply mechanically in all cases. As Table 1 so well illustrates, other factors have to be borne in mind. Time does not operate alone. It merely provides an opportunity for learning. Such factors as age or maturity, aptitude and previous language learning experience, the characteristics of the target language, the curriculum, and teaching methodology, all play a part as well.

\section{Time and Age}

The relationship between amount of time for language learning and age is controversial, because it is not clear whether younger or older people make better language learners. An argument for starting younger is not only the view that younger learners are better learners, but that starting younger increases the amount of time available at a period in the education of a child when there is not so much pressure on the time-table. Against this, however, is the opinion that has most forcibly been 
expressed by Burstall, et al. (1974) and the British Primary French Project, that older learners tend to be more efficient and therefore make better use of the time. This is also the point of view that Carroll (1975) has tended to support in his interpretation of the international study of French in eight countries.

According to recent findings the young learner may have an advantage in social and intuitive ways of language learning while the older learner with more school experience is likely to respond better to the academic aspects of second language teaching (Stern and Cummins, 1981; Swain, $1981 ; 1981 a)$. This would suggest that compact courses which are academically demanding are likely to be handled more efficiently by older and more experienced learners.

\section{Time, Aptitude, and Previous Language Learning Experience}

Another factor that influences the use of time by learners is differences in language learning aptitude. Here again, we are indebted to the thinking of J.B. Carroll. Whatever the components of aptitude, its effect is, according to Carroll, that the learner with greater aptitude can reach the learning objective faster than the learner with less aptitude, or he can learn more in the same amount of time. Consequently, if we want to estimate time needed for typical groups of learners, we must assume that some will have higher and others lower aptitude, and our estimates must take these differences into account. ${ }^{7}$ This would suggest that shorter and more demanding language learning courses will be handled more efficiently by the more able learner, and that those who have had previous language learning experience-especially if they have been trained in techniques of efficient language learning - can probably deal with a more concentrated approach more effectively and with greater confidence.

\section{Time and Differences between Languages}

Intuitively, it is often believed that some languages are more difficult to learn than others for learners of a given language background. For example, it is more difficult for a European with a native-language background in English or French to learn Japanese than another European language, and greater difficulty means that it will take longer to learn the language. Accordingly, the estimates of time in Table 1 have distinguished between four groups of languages graded in difficulty (for English native speakers) and with widely differing time allocations. There is little documentation on what constitutes difficulty of a language for different ethnolinguistic groups of learners, and how such information can be reliably translated into time allowances for language teaching. However, it is a factor to bear in mind in developing compact courses, and in the absence 
of research data we can in this respect only be guided by practical experience.

\section{TIME AND THE COMPACT COURSE CURRICULUM}

Time, as was pointed out above, merely provides the opportunity for language learning. Therefore, what matters is how the time is used. If the time is reduced and more concentrated, as is envisaged for compact courses, this is likely to suggest a different course design, a different lesson pattern, different teaching methods, and materials that are differently constructed from the customary all-purpose long-term language course.

There are a number of recent experiences which can be helpful in re-thinking the curriculum and methodology for compact courses. These trends of recent times can provide useful input, which need not be detailed here: the European communicative syllabus movement, languages for special purposes, graded examinations in Britain, North American and European experiences with individualization of instruction and selfinstruction. All these have in common a clearer specification of objectives and teaching content and the identification of more explicitly stated definitions of mastery levels than had been customary in conventional courses. It follows from the reduction of time in compact courses that objectives and content must also be more precisely stated. However, since the compact courses under consideration by the Marburg Symposium are for general schooling at the secondary stage, it is important not to narrow down content and objectives excessively. In fact, I would suggest that the kind of curriculum design recently discussed by the American Council on the Teaching of Foreign Languages (ACTFL) - with no thought of compact courses-can with advantage be applied to the curriculum development for secondary school compact courses (Stern, 1981). In this scheme a foreign language curriculum - compact or regular - is thought of as having a multiple focus and should have four components (or syllabuses): a language syllabus, a culture syllabus, a syllabus of communicative activities, and a general language education syllabus. (See Figure 1.) There are good reasons to suggest that a curriculum for compact courses should also draw on all four syllabus areas so that the compact course is educationally valid in the context of general education. Moreover, a language course which includes a "general language education" component" ${ }^{9}$ can, under this heading, guide learners to other languages and thus within the context of one language include a multilingual sensitization. Under the conditions of a compact course, each of the four syllabuses must of course be treated very selectively, and I believe the challenge for the future is to suggest course designs, teaching approaches and materials development 


\begin{tabular}{|c|c|c|c|c|c|}
\hline \multirow[t]{2}{*}{ Content } & \multicolumn{4}{|c|}{ Objectives } & \multirow[t]{2}{*}{ Main strategies } \\
\hline & Proficiency & Knowledge & Affect & Transfer & \\
\hline $\begin{array}{l}\text { Language } \\
\text { Syllabus (L2) }\end{array}$ & & & & & $\begin{array}{l}\text { Analytical: } \\
\text { Study \& Practice }\end{array}$ \\
\hline $\begin{array}{l}\text { Culture } \\
\text { Syllabus (C2) }\end{array}$ & & & & & $\begin{array}{l}\text { Analytical: } \\
\text { Study (knowledge) } \\
\text { about C2) }\end{array}$ \\
\hline $\begin{array}{l}\text { Communicative } \\
\text { Activity Syllabus } \\
\text { (L2/C2) }\end{array}$ & & & & & $\begin{array}{l}\text { Communicative } \\
\text { Activities } \\
\text { (Experiential) }\end{array}$ \\
\hline $\begin{array}{l}\text { General Language } \\
\text { Education Syllabus }\end{array}$ & & & & & $\begin{array}{l}\text { Comparative } \\
\text { (Crosslingual/ } \\
\text { Crosscultural) }\end{array}$ \\
\hline
\end{tabular}

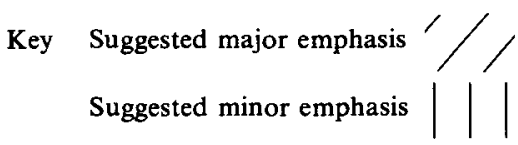

Figure 1. A Foreign Language Curriculum $\mathrm{Model}^{8}$

which are selective without being impoverished.

Since compact courses were envisaged by the Marburg Symposium within a system of such courses or a broader scheme of language education, it is possible to think of single compact courses as "modules" which emphasize limited aspects of the language curriculum, e.g., specified language features, certain cultural items, a well defined program of communicative activities, or selected topics in the general language education area, and within this kind of modular program, in subsequent courses, to shift the emphasis deliberately to other aspects. Such a program of compact courses could be developed as a series within one foreign language or could be multilingual. Variations in content, objectives, timing, sequencing, and teaching approaches suggest an enormous variety of promising possibilities in curriculum design. In materials development, too, it implies a move away from the general textbook or language course series towards smaller and more specific kits, units or "modules" for which experience has already been gathered over the last ten years (Stern, 1976b; Stern, et al., 1980). 


\section{CONCLUSION: FUTURE DEVELOPMENTS}

There is obviously no justification for language courses which are over-extended, poorly designed, badly articulated and repetitive and which consequently are frustrating and ineffective. The concept of compact course has undoubtedly considerable potential to remedy such weak and straggling language programs. It may also provide for a more flexible, and more varied approach to a multilingual education within a school context.

On the other hand, if this innovation is not handled with skill and discretion, it may simply turn out to be another failed panacea to add to the long list of such discarded reforms (Hawkins, 1981). In our enthusiasm for compact courses, it is important to remember that in many countries the issue is not that too much time is squandered in poor foreign language instruction but rather that too little time is made available for effective teaching. In these instances the compact course concept may turn out to be a stick to clobber foreign languages even more into accepting inadequate time allocations. It would be ironic if this were to happen at this stage in the development of language pedagogy when the importance of adequate time and appropriate timing has begun to be recognized and has been a subject of serious reflection and study.

Therefore if the idea of the compact course is to be successfully implemented and is not to backfire, a number of steps need to be taken. To begin with, in planning compact course schemes, it would be important to consider very carefully the implications of the body of experience and research that is available on the question of time and timing - a process that this article has attempted to set in motion.

Secondly, it would be useful to outline a number of different compact course patterns, to determine specific course objectives, to identify the course content, to sketch appropriate time frames, and to suggest timetables and a teaching methodology. The entry level of course participants (age, previous educational and language learning experience) should also be determined.

Thirdly, a number of compact courses should be instituted as pilot experiments. The kinds of curriculum plans, referred to above, and others described for the Marburg Symposium, suggest themselves as a basis to start with.

Fourthly, there should be ongoing (formative) evaluation, and, finally, since the idea was launched internationally through FIPLV, steps should be taken for further international pooling of ideas and exchanging of information on experiments and experiences.

Questions that experiments might consider include: What is a useful length for compact courses at the school level? How should teaching time 
be optimally distributed? How can compact courses be combined into a system of interrelated courses each of which still maintains a certain degree of autonomy? In view of the demands of the total school curriculum, what are practical patterns of arrangement for compact courses? In what way do the teaching approaches in a compact course vary from a conventional course? In terms of learning outcomes, how do compact courses compare with more conventional course designs?

The long-term effects of compact courses should also be investigated. There is a suggestion that the rate of loss of proficiency in intensive language teaching is much higher than in more distributed ways of language learning. Can compact courses be most effectively combined with a distributed (spaced) follow-up? The findings on massed and distributed learning in psychology and research on retention and attrition in language learning should be borne in mind.

The compact course format is a challenging and potentially useful variation in the planning of language teaching. If handled judiciously it could make a substantial contribution to a more varied and more flexible approach to language teaching at the school and university level. Openmindedness, willingness to experiment, and a research outlook are needed to ensure that this innovation is successfully introduced into school curricula.

\section{FOOTNOTES}

1. Adapted from the preamble of the final report on the Marburg Symposium.

2. Interesting present-day applications of intensive language training may be found in the Canadian public service. This language training can hardly be described as "compact" because the total number of hours allowed for is generous by school standards. Here is how the courses are described in the students' handbook:

"The time that you spend on training depends on several factors: the most important is, of course, the level you have to attain; another is your "rate of learning," or how quickly you can learn a second language. Present policies allow a student to spend a maximum of 1,560 hours of training to attain his or her required proficiency level. An extra 780 hours are granted if the student is required to reach a higher level after attaining one level of proficiency." (Canada 1979:15) See also Wesche (1981).

3. This table of time allowances has also been reproduced by Jakobovits $(1970$, p. 233) and, in turn, by Ingram (1975, p. 272) in the Edinburgh Course in Applied Linguistics, vol. 2.

4. See on this point the studies referred to in Note 6 below.

5. On this large-scale investigation see Stern, et al. (1976a) and a special issue of the Canadian Modern Language Review (Nov. 1976) with several papers and discussions on this project (e.g., Stern, 1976).

6. For explanations of Ontario language education policy and references see Stern (1979). It should be pointed out that time and second language learning do not always operate in this direct and linear fashion as was believed by some educators in the early 1970s. Recent studies suggest that the patterns of relationship between "time and 
timing" of language learning and proficiency may be influenced by many other factors, including social and interpersonal experiences and cognitive maturity (see Swain, 1981a and 1981b). For a more recent discussion of research on time and timing, see Stern (1982).

7. On recent experiences with using aptitude measures as predictors of the time needed for language training see Wesche (1981).

8. This scheme is based on curriculum ideas jointly developed in the 1970 s with $R$. Ullmann in the Modern Language Centre of the Ontario Institute for Studies in Education (OISE). (See Stern, 1976a; Stern, et al., 1980.)

9. This component is similar to Hawkins" (1981) proposal of training in "awareness of language."

\section{REFERENCES}

Benseler, D.P. \& Schulz, R.A. (1979). Intensive Foreign Language Courses. Language in Education Series, No. 18. Washington, D.C.: CAL/ERIC.

Burstall, C., Jamieson, M., Cohen, S., \& Hargreaves, M. (1974). Primary French in the balance. Slough, U.K.: NFER.

Canada, Public Service Commission (1979). A Student's Handbook. Ottawa: Ministry of Supply and Services.

Carroll, J.B. (1963). A model of school learning. Teachers College Record, 64, 723-733.

Carroll, J.B. (1967). Foreign language proficiency levels attained by language majors near graduation from college. Foreign Language Annals, 1, 131-151.

Carroll, J.B. (1975). The teaching of French as a foreign language in eight countries. New York: Wiley.

Cleveland, H., Mangone, G.J., \& Adams, J.C. (1960). The overseas Americans: A report on Americans abroad. New York: McGraw-Hill.

Hawkins, E. (1981). Modern languages in the curriculum. Cambridge: Cambridge University Press.

Hawkins, E., \& Perren, G.E. (Eds.) (1978). Intensive language teaching in schools. London: Centre for Information on Language Teaching and Research.

Ingram, E. (1975). Psychology and language learning. In J.P.B. Allen and S.P. Corder (Eds.), Papers in applied linguistics. Edinburgh Course in Applied Linguistics II, 218-290.

Jakobovits, L. (1970). Foreign language learning: A psycho-linguistic analysis of the issues. Rowley, Mass.: Newbury House.

Stern, H.H. (1976a). The Ottawa-Carleton French project: Issues, conclusions, and policy implications. Canadian Modern Language Review, 33, 216-232.

Stern, H.H. (1976b). Mammoths or modules. London Times Educational Supplement, October 8 (special insert on modern language teaching, p. 44).

Stern, H.H. (1979). Of honeymoons, hangovers, and bootstraps in foreign language teaching. The Modern Languages Twentyman Lecture. Modern Languages, 60, 1-9.

Stern, H.H. (1981). Directions in foreign language curriculum development. In P.L. Lange and C. Linder (Eds.), Proceedings of the National Conference on 
Professional Priorities. Hastings-on-Hudson, N.Y.: ACTFL Materials Center, 12-17.

Stern, H.H. (1982). Issues in early core French: A selective and preliminary review of the literature 1975-1981. Research Service \#163. Toronto: Research Department, Board of Education of the City of Toronto.

Stern, H.H., \& Cummins, J. (1981). Language teaching/language research: A Canadian perspective on status and directions. In J.K. Phillips (Ed.), Action for the '80s: A political, professional, and public program for foreign language education. ACTFL Foreign Language Series. Skokie, Ill.: National Textbook Company, 195-248.

Stern, H.H., Swain, M., McLean, L.D., Friedman, R.J., Harley, B., \& Lapkin, S. (1976) Three approaches to teaching French. Toronto: Ontario Ministry of Education.

Stern, H.H., Ullmann, R., Balchunas, M., Hanna, G., Schneiderman, E., \& Argue, V. (1980). Module making: A study in the development and evaluation of learning materials for French as a second language. Toronto: Ontario Ministry of Education.

Swain, M. (1981a). Linguistic expectations: Core, extended and immersion programs. Canadian Modern Language Review, 37, 486-497.

Swain, M. (1981b). Time and timing in bilingual education. Language Learning, $31,1-15$.

U.S.A. (1979). Strength through wisdom: A critique of U.S. capability. Report of the President's Commission on Foreign Language and International Studies. Washington, D.C.: Government Printing Office.

Wesche, M.B. (1981). Language aptitude measures in streaming, matching students with methods and diagnosis of learning problems. In K.C. Diller (Ed.), Individual differences and universals in language aptitude. Rowley, Mass.: Newbury House, 119-154.

\section{THE AUTHOR}

H.H. (David) Stern is Professor Emeritus in the Department of Curriculum of the Ontario Institute for Studies in Education (OISE), University of Toronto, and a Killam Research Fellow (1982-85). He was the founding director of the Modern Language Centre of the Ontario Institute for Studies in Education, a position he held from 1968-1981. He now works as a freelance language consultant, author, and lecturer.

David Stern is the author of several books, articles, and research reports on language teaching. One of his most recent books, Fundamental Concepts of Language Teaching, was published by Oxford University Press in 1983 . He is at present working on a continuation of this work with a focus on language teaching methodology. 
